\title{
314 Optimization on Crush Characteristics of Cylindrical Origami Structure
}

Xin TAO, Tokyo Institute of technology, Ookayama2-12-1, Meguro-ku,Tokyo

Ichiro HAGIWARA, Tokyo Institute of technology

Chihiro YAMAMOTO, Huji Heavy Industries Ltd.

Taketoshi NOJIMA, Kyoto University

\begin{abstract}
It has been clearly shown that a can or PET bottle made by origami technique can be crushed with much smaller force. Furthermore, this structure is desirable to absorb more crash energy during automobile light collision or vehicles-pedestrian accidents. Thus, in this research, to minimize average crashing force of the origami structure, the shape of the structure and the angle of polygonal folding lines are optimized by the method of MPOD, one kind of Response Surface Methods based on Holographic Neural Network
\end{abstract} (HNN).

Key Words: Origami technique, Computational Engineering, Crash Characteristics, Optimization, MPOD

\section{Introduction}

Origami technique is used in our common life to fold paper toys. It can change one piece of paper into various solid objects and then easily restore it back. By utilizing this characteristic, scientists have found out this folding/deploying technique can be diverted to devise many new industrial products.

Foldable structures made by origami models have been widely investigated in the last several years. Nojima has designed some origami models expected to be applied to Aeronautical and space structures. Hagiwara et al. have tried some new models to design a new kind of beverage container that can be easily folded after usage.

In this research, we focus eyes on the field of pedestrian protection solution methods in vehicles-pedestrian accidents. To judge vehicles' performance on pedestrian protection, one of the most important indexes is the crush characteristic of bumped vehicle parts. If these parts could absorb more crush energy during accidents, the energy absorbed by human could be reduced accordingly, thus pedestrian could be better protected. To realize this purpose, it requires that these parts could be transformed more easily during accidents.

On this basis, reversed spiral cylindrical origami structure is proposed as one solution method and its crush characteristic are analyzed by using the method of FEM (Finite Element Method). Study results showed that origami structure agrees well with FEM analysis requirements. Thus, to minimize the crush force and maximize crush zone got from FEM analysis, the structure is optimized by the method of MPOD (Most Probable Optimization Design), one kind of Response Surface Methods based on Holographic Neural Network.

The mathematical theory of reversed spiral cylindrical origami structure is introduced in the first chapter, followed by the structure analysis of the model. Optimization procedure and the FEM analysis simulation results are then discussed. Finally, we present some tentative conclusions and recommendations for further study.

\section{Origami Techniques for Cylindrical Folding}

\subsection{Cylindrical folding}

Folding method is being generalized by Nojima ${ }^{1}$. Many folding patterns have been developed in the past several years. Here we focus on one kind of folding method-cylindrical folding. Consider the following belt-like paper in fig.1. After bended along the lines on it, the paper becomes a cylinder- like structure, whose important character is that it can be easily crushed from a solid to a plane. This kind of folding method is called cylindrical folding.

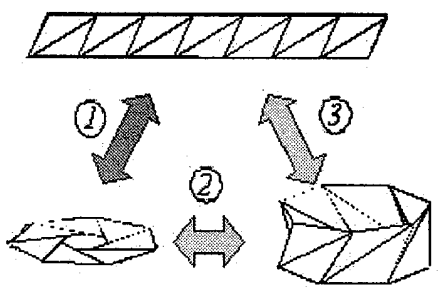

Fig.1 Image of origami structure folding procedure

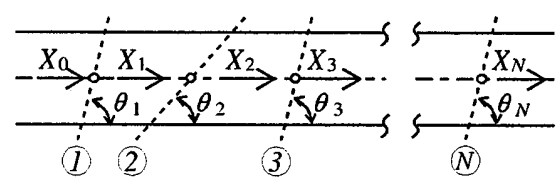

Fig.2 Folding lines in a stripe 


\subsection{Folding condition}

The folding condition for cylindrical folding can be detected from one strip as shown in Fig. 2. The angles composed by bending lines(1), (2) - Nand the central line $X$ are labeled $\theta_{1}$ $\theta_{2} \ldots \theta_{\mathrm{n}}$ and the breadths between each bending lines along central line are named $X_{1}, X_{2}, \ldots X_{\mathrm{n}}$ respectively. (See fig.2)

It has been proved that when a paper sample is perfectly folded, it must meet the following conditions.

a), The bending lines do not intersect with each other within every breadth.

b), The bending lines are not vertical with the central line.

c), Two sides of both ends are consistent with each other after folding.

d), The positions of both ends are consistent after folding.

e), No twist occurs during folding.

\subsection{Mathematical theory}

Label the angle between $\theta_{i}$ and $X_{i}$ as $\Theta_{i}$. According to the fundamental considerations described above, the following equation is detected. This means, a paper sample could only be perfectly folded if $\Theta_{\mathrm{N}}=2 \pi$.

$\Theta_{N}=2\left(\theta_{1}-\theta_{2}+\theta_{3}-\cdots-\theta_{N}\right)=2 \pi$

As it is very difficult to get the solution of above equation, let us take one unit of the strip as an example. (See fig.3) The angle $B_{1} A_{1} B_{2}$ is labeled $\alpha$ and the angle $B_{2} A_{1} A_{2}$ is labeled $\beta$.

It can be easily seen that the paper is periodically folded. To keep two sides of both ends consistent with each other after folding, it must be folded an odd number of times. Thus equation (1) can be expressed to

$$
\left\{\begin{array}{l}
\theta_{1}=\beta \\
\theta_{2}=\alpha+\beta \\
\theta_{3}=\beta \\
\theta_{4}=\alpha+\beta \\
\vdots \\
\theta_{N}=\beta
\end{array}\right.
$$

Substitute (2) for (1), the perfect folding condition is given as

$\Theta_{N}=2\left(\frac{N}{2} \alpha\right)=2 m \alpha$

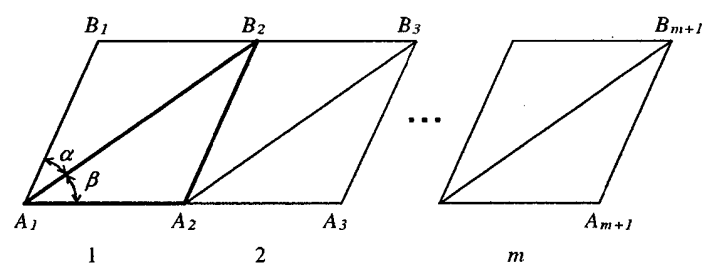

Fig.3 Developments to form foldable cylinder where $\mathrm{N}=2 m$. Then the final result is

$\alpha=\pi / m$

\section{Crushing Characteristic with FEM}

\subsection{Origami structure model for FEM analysis}

In this research, reversed spiral cylindrical-like origami structure is selected as our analysis model (Fig. 3), which is gotten by connecting two of the cylindrical folding stripe shown in Fig.1 in a reversed way. The most important advantage of this structure is, no matter where the structure is used, the top and bottom face can be fixed without adding extra force on it during crushing.

The structure was crushed by a rigid wall with the initial speed of $3 \mathrm{~m} / \mathrm{s}$ and the mass of $1000 \mathrm{~kg}$. All the analysis conditions are listed in Table 1.

\subsection{FEM analysis results}

Crushing characteristic analysis was executed by using FEM analysis software LS-DYNA. Lateral surface was divided into triangular and rectangular meshes and movements of the upper and lower surfaces were all restrained except the displacement of crushing direction.

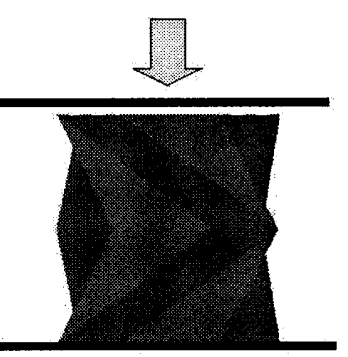

Fig.4 Origami structure model for FEM

Table 1 FEM analysis conditions

\begin{tabular}{|c|c|c|}
\hline \multirow{4}{*}{$\begin{array}{c}\text { Origami } \\
\text { Structure }\end{array}$} & Material & aluminum \\
\cline { 2 - 3 } & Density & $2820 \mathrm{~kg} / \mathrm{m}^{3}$ \\
\cline { 2 - 3 } & Young's modulus & $70 \mathrm{GPa}$ \\
\cline { 2 - 3 } & Poisson's ratio & 0.33 \\
\cline { 2 - 3 } & Yield stress & $100 \mathrm{MPa}$ \\
\cline { 2 - 3 } & train-hardening rati & $280 \mathrm{MPa}$ \\
\cline { 2 - 3 } & Thickness & $0.2 \mathrm{~mm}$ \\
\cline { 2 - 3 } & Circumscribed & $\varphi 100 \mathrm{~mm}$ \\
\cline { 2 - 3 } & Height & $100 \mathrm{~mm}$ \\
\hline Rigid Wall & Weight & $1000 \mathrm{~kg}$ \\
\hline & Initial Speed & $3 \mathrm{~m} / \mathrm{s}$ \\
\hline
\end{tabular}




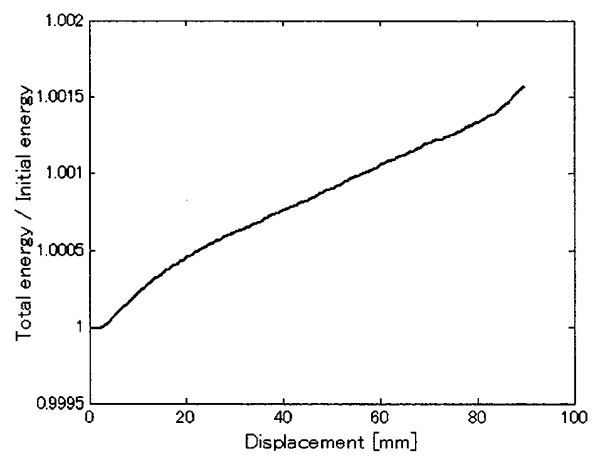

Fig.5(a) Energy transition

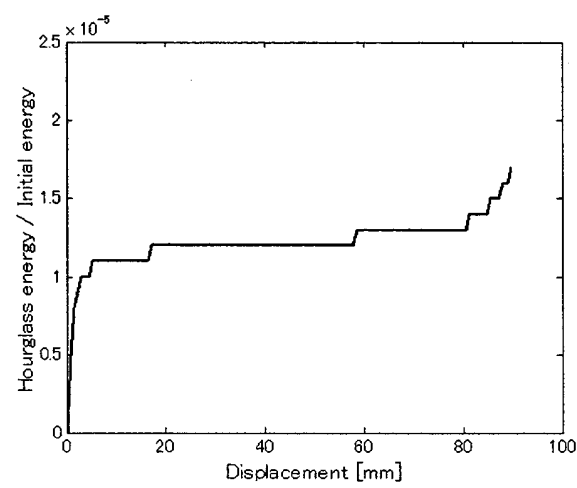

Fig.5(b) Hourglass energy transition

Fig.5 Analysis results with Hexagonal cylindrical model

When performing FEM analysis, it is necessary to fulfill energy preservation law and to check whether Hourglass energy is small enough. In order to fulfill energy preservation law, the ratio of the energy at the time of an analysis start (movement energy) and intermediate energy (sum of movement energy and internal energy) needs to be close to 1 . For hourglass energy, it becomes large when the element type or element division is not appropriate, which always influences calculation accuracy.

Figure 5 shows energy transition and hourglass energy transition of Hexagonal cylindrical model with FEM analysis, which element side equals to $9 \mathrm{~mm}$. It can be seen that the general trend is for both ordinates to increase steadily as displacement increases. This is because structure energy increases unavoidably during crushing. However, since the error ratios are no more than $0.15 \%$ and $0.025 \%$, the calculation results indicate that reversed spiral cylindrical-like origami structure agrees well with FEM analysis conditions.

From Figure 5 it can also be seen, the origami structure can be disfigured beyond $90 \%$ of the whole height. Consider that crushing force for the present vehicle parts increases sharply after transformed more than $70 \%$, these characteristics are especially significant.

\section{MPOD Optimization with FEM}

Although theoretically origami structure could only be perfectly folded when $\alpha=\pi / m$, according to previous research, average crushing force can be reduced when a slight gap of $\alpha$ occurs.

Based on this theory, surface division number $m$ and gap $\gamma$ are used as design variables of optimization. The correlation between number $m$ and gap $y$ can be expressed as

$$
\alpha=(1+0.01 \gamma) \pi / m
$$

Objective function is the average crushing force on displacement. Restraint conditions of design variables are $4 \leqq m$ $\leqq 10,-5 \leqq \gamma \leqq 2$. All of the FEM analysis conditions remain the same.

Optimization method is Holographic Neural Network based most probable optimization design method -MPOD. Flow chart of MPOD method is shown in Figure 6.

The procedure of MPOD can be briefly divided into two steps; one is the search for the field that includes optimum point, and the other one is the finding of optimum point.

For the first step, we choose initial study points from the whole field randomly, then use Response Function Estimation to find the range which has the highest possibility of including optimum point. Number of study point at this stage is decided as

$$
N=\left(n_{d v}+1\right)\left(n_{d v}+2\right) / 2
$$

where $n_{d v}$ is the number of design variables.

Furthermore, to get the correct optimization result by using least study points, it requires that the points should be distributed as equally as they could. Thus, minimum distance between any two study points is defined as

$$
\left.d_{\min } \leq \min \|\left(x_{i}\right\}-\left\{x_{j}\right\}\right) \quad(i, j=1,2, \ldots, N, i \neq j)
$$

After study points are decided, we perform the second step by using $\mathrm{HNN}$ response surface approximation to get final optimum point.

As shown in Fig6, the first we calculate optimum point $\left\{\hat{x}_{k-1}^{*}\right\}$ amongst initial study points. After that, new study points got from random number of $\sigma$ are added into initial points and new optimum point $\left\{\hat{x}^{*}{ }_{k}\right\}$ is calculated. Here $\sigma$ is

$$
\sigma=\alpha\left\|\left\{\hat{x}_{k}^{*}\right\}-\left\{\hat{x}_{k-1}^{*}\right\}\right\|
$$

The above procedure is repeatedly produced until the remainder between $\left\{\hat{x}_{k}^{*}\right\}$ and $\left\{\hat{x}_{k-1}^{*}\right\}$ is smaller than convergence test $\varepsilon_{1}$.

$$
\left\|\left\{\hat{x}_{k}^{*}\right\}-\left\{\hat{x}_{k-1}^{*}\right\}\right\| \leq \varepsilon_{1}
$$




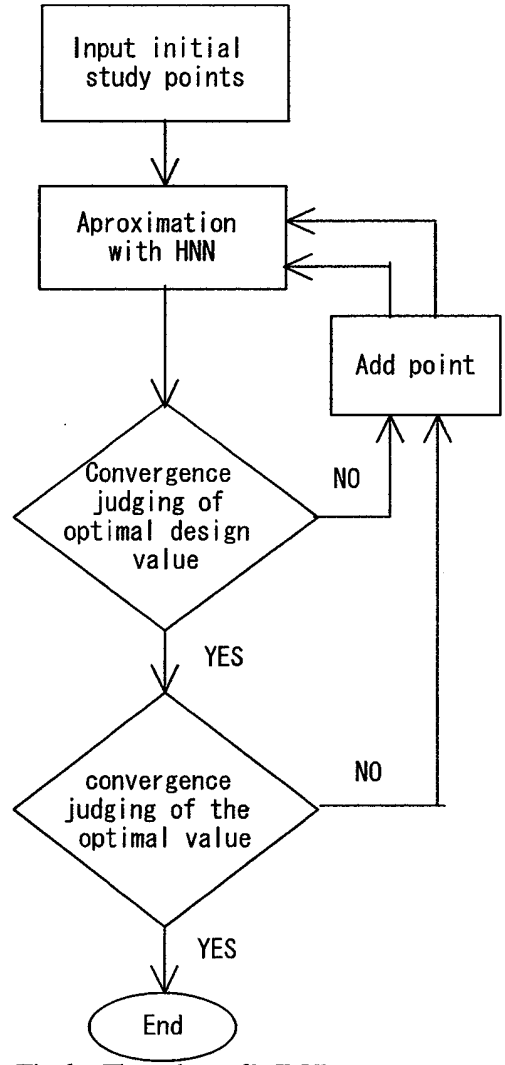

Fig 6 Flow chart of MPOD

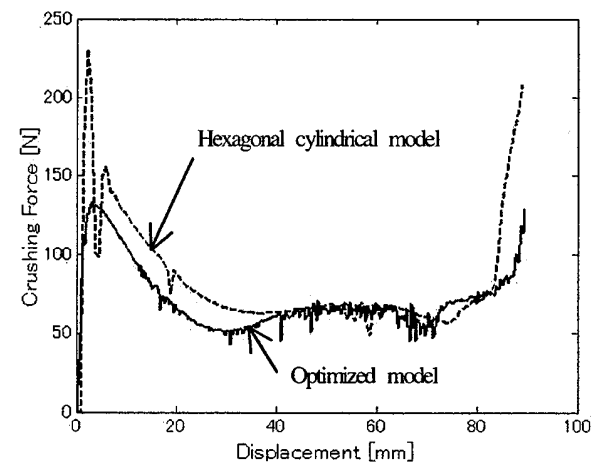

Fig.7 Crash characteristics

In addition, since $\left\{\hat{x}_{k}^{*}\right\}$ is got from last procedure is the approximation value with $\mathrm{HNN}$, we still need to do convergence judging of optimal value by using formula 13

$$
\left\|f\left(\left\{\hat{x}_{k}^{*}\right\}\right)-\hat{f}\left(\left\{\hat{x}_{k}^{*}\right\}\right)\right\| \leq \varepsilon_{2}
$$

where $f\left(\left\{\hat{x}_{k}^{*}\right\}\right)$ is the real optimum value, $\hat{f}\left(\left\{\hat{x}_{k}^{*}\right\}\right)$ is approximation value with $\mathrm{HNN}$. The calculation can not be stopped until formula 13 is also satisfied. $\left\{\hat{x}_{k}^{*}\right\}$ to the last is the final optimum point.

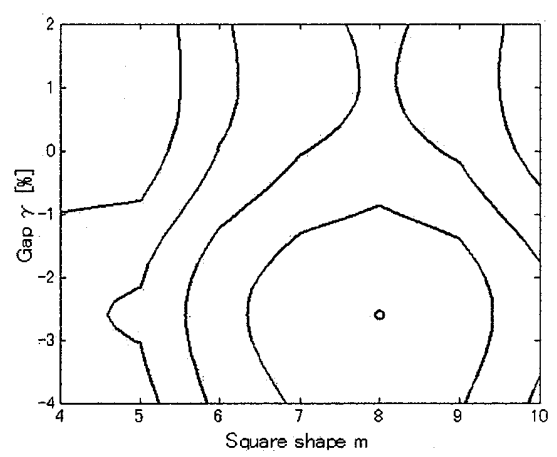

(i) Contourline graphic

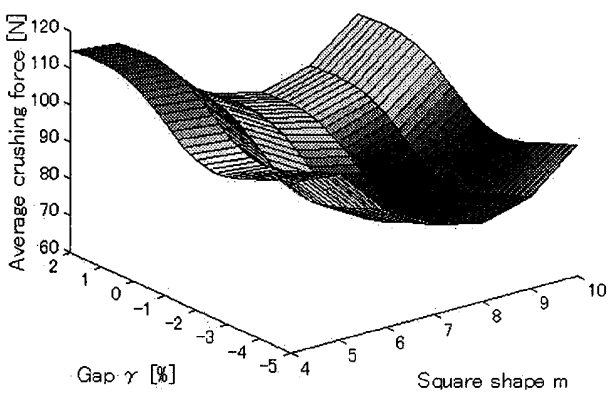

(ii) Response surface

Fig.8 FirststageduningMPOD calulation

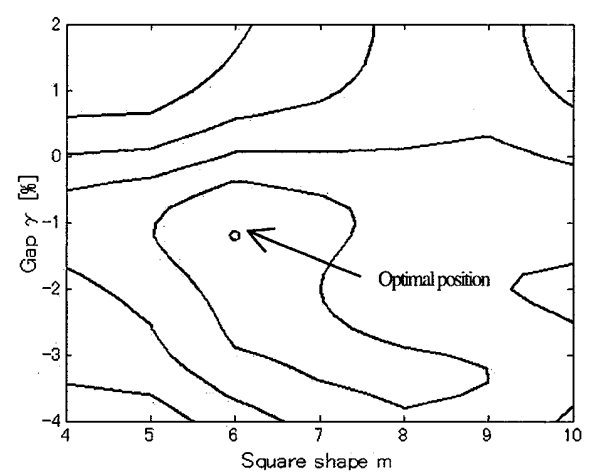

(i) Contourmap

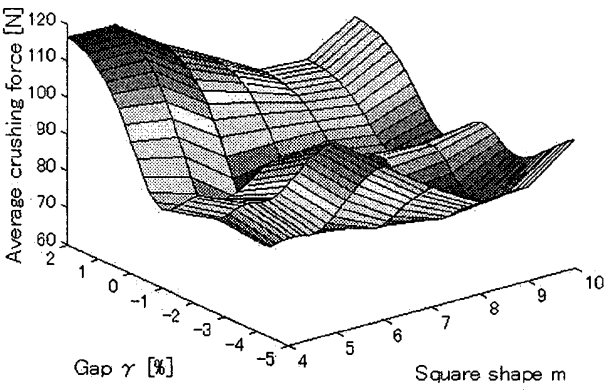

(ii) Responsesurface

Fig.9 Final stageduningMPOD calculation 
In this research, $\varepsilon_{1}=\varepsilon_{2}=00.8$. Optimization calculation finished when study points increased to 19 points and gap $\gamma$ equals $1.2 \%$. From Fig7 it can be seen, the crashing force has decreased greatly during the first and final stages after optimization. The average crushing force got from FEM is $71.8 \mathrm{~N}$, while it changes to $65.5 \mathrm{~N}$ after optimization.

Transitions of optimum point in calculation are presented in figure 8 and figure9; figure 8 is the HNN response surface with initial study points, figure9 is the final $\mathrm{HNN}$ response surface. From (i) Contour line graphic it can be seen that position of optimum point has changed greatly. In (ii) Response surface, it shows that the minimum value of average crushing force is also greatly reduced.

\section{Conclusion and discussion}

Based on the FEM analysis results, MPOD optimization is performed in this research. The theoretical and computer simulation study are summarized as follows:

(1) FEM calculation results indicate that reversed spiral cylindrical-like origami structure agrees well with FEM analysis conditions. Thus, the simulation results got from FEM analysis are reliable.

(2) From FEM calculation results it can also be seen that, the origami structure can be disfigured beyond $90 \%$ of the whole height. Consider that crushing force for the present vehicle parts increases sharply after transformed more than $70 \%$, these results are especially significant.

(3) to minimize average crashing force of the origami structure, the shape of the structure and the angle of polygonal folding lines are optimized by using Holographic Neural Network based MPOD optimization method. Study results show that crashing force has decreased greatly during the first and final stages, and average crushing force is also reduced about $8.7 \%$ after optimization.

However, since all our research data are got from computer calculation, we still need to do experiment to judge the reliability of these results in future. In addition, to better protect pedestrian in accidents, besides average crushing force, the optimization of crushing energy is also in demand.

\section{Reference}

(1) 野島武敏、平板と円筒の折りたたみ法の折紙によるモデル

化、機論C、Vol.66,No.643(2000/4), pp.1050-1056.

(2) 野島武敏、数理折り紙による構造モデルー折紙工学の提案

一、京都新聞2002年 11 月 27 日朝刊「京都大学国際融合創造セン ター(IIC) フェア」.

（3）萩原一郎、灘吉聡、折り紙工学を利用した円筒構造物の圧 潰解析、自動車技術会論文集Vol.34,No.4(2003/10)に揭載決定

（4）施勤忠、萩原一郎、高島太、応答曲面法による多峰性問題

の最適設計法の開発、機詇、Vol.65,No.630(1999-2), pp.232-239.

(5) LS-DYNA3D THEORETICAL MANUAL

(6)萩原一郎、シミュレーションによる衝突解析、自動車技術

Vol.33 №3 (1979) 、pp.154-159.

(7)永島豪、野島武敏、折りたたみ可能な円筒の製作とその伸縮特性、 日本機械学会第回機械材料・機械加工技術講演論如乘)、151152 